\title{
A IMPORTÂNCIA DA CONTROLADORIA EM EMPRESAS FRANQUEADAS
}

\author{
Lucilene Gomes dos Santos, Eduardo Teraóka Tofoli
}

Universidade do Oeste Paulista - UNOESTE, curso de Finanças e Controladoria, Presidente Prudente, SP. E-mail: luvidanova2008@hotmail.com; eduardo tofoli@yahoo.com.br

\section{RESUMO}

Com o movimento de expansão do sistema de franquias no Brasil e o enfoque que a Controladoria vem alcançando nas últimas décadas, percebe-se a necessidade de estudo na área, uma vez que todo e qualquer tipo de comércio precisa manter um sistema de controle eficaz para alcançar os objetivos traçados. Este estudo pretende analisar a importância da controladoria em uma empresa franqueada e foi desenvolvido por meio de pesquisa bibliográfica e descritiva e como resultado verificou-se que a maioria das franqueadas citadas e pesquisadas nas bibliografias encontradas sobre o assunto não utilizam formas de controles adequados em suas operações, uma vez que o controle maior se dá através das franqueadoras. Conclui-se que é de suma importância que mesmo com os controles estabelecidos pelas franqueadoras, controles internos próprios e individuais têm que ser implantados para melhor alcance dos objetivos.

Palavras-chave: franquias, franqueadas, controladoria, vantagens.

\section{THE IMPORTANCE OF CONTROLLING IN SELECTED ENTERPRISES}

\begin{abstract}
With the movement of expansion of the franchise system in Brazil and the focus that the Controller has achieved in the last decades, it is necessary to study in the area, since any type of trade must maintain an effective control system for Objectives. This study intends to analyze the importance of the control in a franchised company and was developed through bibliographical and descriptive research and as a result it was verified that the majority of franqueadas cited and researched in the bibliographies found on the subject do not use forms of adequate controls in their Operations, since the greater control is given through the franchisors. It is concluded that it is of the utmost importance that even with the controls established by the franchisors, internal and individual internal controls have to be implemented to achieve the objectives.
\end{abstract}

Keywords: Franchises, franchisees, controller, advantages.

\section{INTRODUÇÃO}

A expansão do mercado de franquias no Brasil, principalmente na última década, tem sido bastante significativa. Nesse contexto pode-se perceber que um dos fatores de destaque que ocasionou a explosão de franquias foi a enorme divulgação quanto à viabilidade econômica desse tipo de negócio que, apesar de apontar alguns fatores negativos, ainda possuem pontos interessantes. Uma das áreas que pode auxiliar nessa gestão, é a controladoria.

A Controladoria é parte indispensável em todos os tipos de negócios e tem fundamental importância na realização de suas atividades para manter um controle estruturado e eficaz, mantendo assim a saúde financeira da empresa e melhor condição, não só de crescimento, mas de permanência no mercado de negócios que a cada dia se torna mais competitivo.

A Controladoria tem a finalidade de dá suporte, para as tomadas de decisões dentro de uma empresa, ele utiliza as demonstrações feitas pela contabilidade, faz as análises dos dados ligados ao orçamento e ao planejamento empresarial para depois dar o seu parecer. Ela também 
pode utilizar-se de quaisquer outras ferramentas de informação, pode se apoiar nas informações geradas pela administração da produção, da estrutura organizacional e também da administração financeiro.

A Controladoria é utilizada para dar suporte aos administradores das empresas, não importando em que área as informações serão utilizadas, o controller agirá como um tradutor das demonstrações contábeis.

Nesse sentido a presente pesquisa tem como objetivo analisar a importância que a controladoria traz para uma empresa franqueada, uma vez que esse modelo de negócio segue regras e normas diferentes dos demais comércios onde o proprietário tem mais liberdade na redução de custos e composição de preço final dos produtos ofertados.

\section{METODOLOGIA}

Segundo Fleury, Wanke e Figueiredo (2009) em um trabalho, a metodologia de pesquisa possui grande importância devido à necessidade de embasamento científico adequado que o trabalho exige. Portanto, constantemente é necessário procurar pela melhor abordagem de pesquisa a ser utilizada para o correto direcionamento das questões da pesquisa, assim como os métodos e técnicas utilizados para o planejamento e condução. Utilizando-se dessas informações, o trabalho de pesquisa deve proporcionar direta ou indiretamente a geração de conhecimento.

Quanto aos métodos, foi escolhida a Pesquisa Descritiva por ser mais objetiva e não aprofundada. Além disso, segundo Sousa (2006, p.322), "a pesquisa descritiva procura descrever, identificar, analisar e relatar, sem interferir ou manipular o resultado".

No procedimento também foi utilizado a pesquisa bibliográfica que, segundo Cervo e Bervian (1983, p. 55) "explica um problema a partir de referências teóricas publicadas em documentos". Além de ser a que mais dá suporte à pesquisa descritiva por colher informações e conhecimentos já existentes para analisar problemas para o qual se busca respostas.

\section{REFERENCIAL TEÓRICO}

\section{Franchising}

Conforme pesquisa do Serviço Brasileiro de Apoio às Micro e Pequenas Empresas (SEBRAE, 2016), as franquias tiveram seu início no Brasil em 1980, com a pioneira O Boticário, mas a partir de 1985 as empresas começaram realmente adotar o Sistema de Franquias com a intenção de expandir seus negócios, mas sempre com a preocupação de selecionar seus representantes e aumentar a importância da marca dos produtos na visão dos consumidores.

Ainda conforme dados do SEBRAE (2016), em 1987 foi criada a Associação Brasileira de Franchising (ABF) tendo sua sede em São Paulo e como missão a divulgação, defesa e promoção do sistema de franquias em todo território brasileiro.

De acordo com Simão Filho $(1993$, p.35) pode-se definir Franchising como:

Um sistema que visa a distribuição de produtos, mercadorias ou serviços em zona previamente delimitada, por meio de cláusula de exclusividade, materializado por contrato(s) mercantil(is) celebrado(s) por comerciantes autônomos e independentes, embuídos de espírito de colaboração estrita e recíproca, pelo qual, mediante recebimento de preço inicial apenas e/ou prestações mensais pagas pelo franqueado, o franqueador lhe cederá, autorizará ou licenciará para uso comercial, propriedade incorpórea constituída de marcas, insígnias, título de estabelecimento, know-how, métodos de trabalho, patentes, fórmulas, prestando-Ihe assistência técnica permanente no mercado específico.

Dados coletados pela ABF em 2016, afirma que 36\% das 50 maiores marcas de franquias pesquisadas eram do segmento de alimentação, perdendo somente para os serviços educacionais 
que chegaram a $18 \%$ no mesmo ano. Na figura a baixo pode-se ter uma visão geral de como estão distribuídos os seguimentos das franquias no Brasil.

\section{Figura 1}

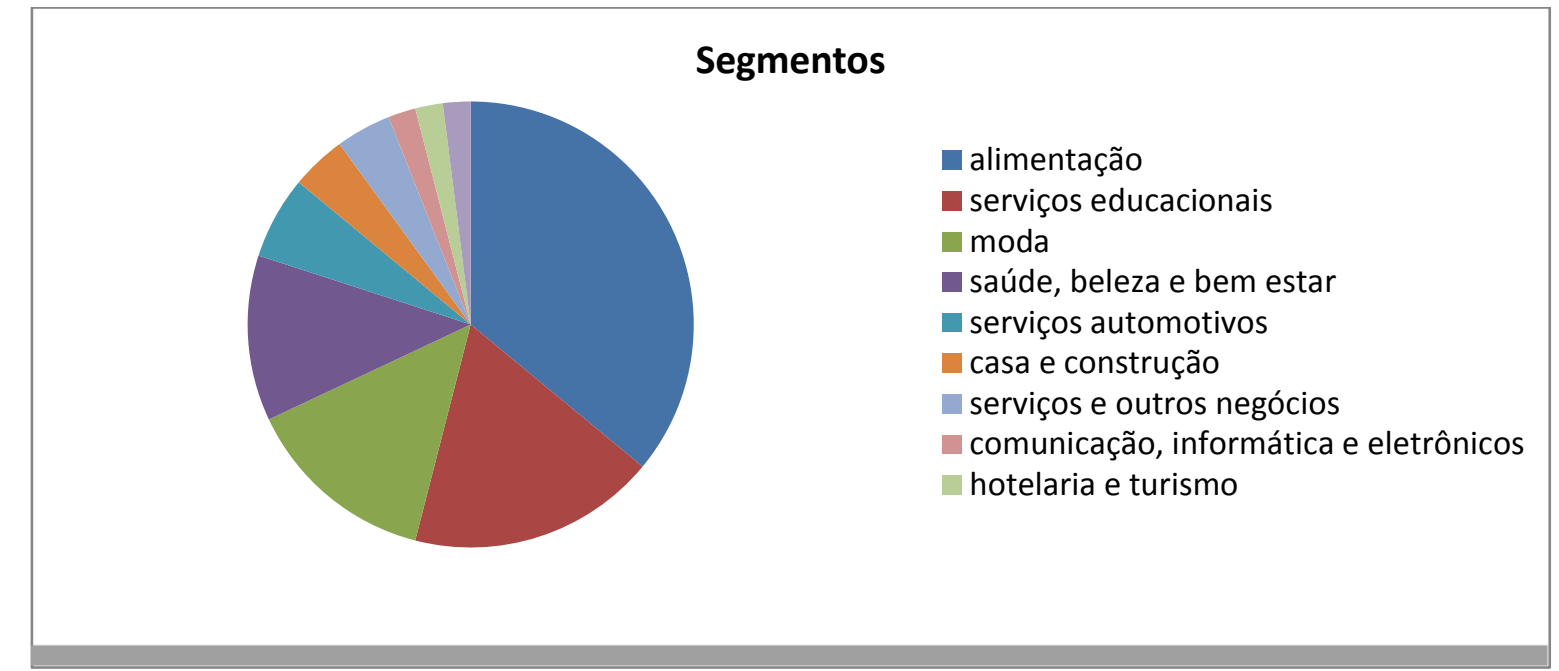

Fonte: ABF, 2016.

\section{Vantagens e desvantagens do franqueado}

De acordo com Martins (2010) apesar da independência do franqueado e da sua autonomia que elimina qualquer tipo de vínculo empregatício com a empresa franqueadora, muitas regras são impostas nos contratos fazendo com que o campo de ação fique restrito. Ressalta ainda que:

[...] existem contratos de franquia que fazem com que o franqueado só pratique determinados atos com autorização expressa do franqueador propaganda local ou regional, apresentação dos produtos, disposição dos mesmos nos estabelecimentos, escrita especial, fornecimento diário, semanal ou mensal de uniformes sobre o movimento financeiro do franqueado, até mesmo o uso de uniformes padronizados pelos vendedores do franqueado [...] (MARTINS, 2010, p. 442).

Beto Filho et al (2013, p. 49), explica que "Franquear significa outorgar, conceder, dar acesso. Significa tornar franco, aberto, disponível, algo que era fechado, secreto, exclusivo." Mas esse sistema de negócio também tem vantagens e desvantagens conforme demonstrado no quadro abaixo.

Quadro 1 - Vantagens e desvantagens para o franqueado

\begin{tabular}{|c|c|}
\hline VANTAGENS & DESVANTAGENS \\
\hline $\begin{array}{l}\text { - Pega "carona" num conceito comercial já } \\
\text { - } \text { - Ostado e aprovado pelo público. } \\
\text { - Pode se concentrar no negócio fim: } \\
\text { vender mais e melhor em seu } \\
\text { estabelecimento. } \\
\text { - Acessa a experiência acumulada do } \\
\text { franqueador e da rede. } \\
\text { - Compra mais barato por participar de } \\
\text { uma maior escala de compras. }\end{array}$ & $\begin{array}{l}\text { - Precisa acatar as diretrizes do } \\
\text { franqueador. } \\
\text { - Tem crescimento limitado. } \\
\text { - Não constrói valor de marca própria. } \\
\text { - A liquidez de seu negócio depende de } \\
\text { cláusulas contratuais previamente } \\
\text { estabelecidas. } \\
\text { - Tem seu desempenho em parte } \\
\text { atrelado ao desempenho da rede e do } \\
\text { franqueador }\end{array}$ \\
\hline
\end{tabular}

Colloquium Socialis, Presidente Prudente, v. 01, n. Especial 2, Jul/Dez, 2017, p.873-879. DOI: 10.5747/cs.2017.v01.nesp2.s0242 
- Recebe serviços iniciais e contínuos: de apoio na implantação e de suporte operacional.

- Rateia custos de propagandas e outros que atingem a rede como um todo.

- Não está sozinho, tem a quem recorrer em caso de problemas, atua em rede.

- Participa de negócios mais estruturados com maior acesso a métodos, sistemas e informações.

- Expõe-se, em princípio, a menor risco do que num negócio independente.

Fonte: Adaptado Beto Filho et al (2013, p. 49 e 50)
- Pode sofrer por ineficiências logísticas ou de suprimento do franqueador.

- Vai rapidamente descobrir que o franqueador não é aquela babá onipresente que esperava.

- Paga na entrada e mensalmente pelas vantagens.

\section{Controladoria}

Segundo Mosimann e Fisch, (1999, p. 88) "a controladoria consiste em um corpo de doutrinas e conhecimentos relativos à gestão econômica", tendo como missão principal garantir informações adequadas para serem utilizadas no processo de planejamento e tomada de decisões assegurando a continuidade das organizações.

Padoveze (2009), explica a controladoria como uma unidade administrativa que utiliza de todo o conjunto da Ciência Contábil da empresa para um melhor planejamento estratégico do trabalho desenvolvido a fim de obter o retorno financeiro esperado.

Para entender melhor como funciona a Controladoria nas empresas Kanitz (apud Mosimann e Fisch, 1999. p. 90) frisa a importância da implantação dos sistemas de informação, motivação, coordenação, avaliação, planejamento e acompanhamento e que o departamento de controladoria é responsável pelo projeto, elaboração, formatação e controle das informações financeiras e contábeis.

\section{Controladoria Empresarial}

A controladoria organiza as informações e mantem o monitoramento para saber se a empresa está ou não caminhando para atingir os objetivos, permitindo uma gestão econômica eficaz. Entretanto, nem todas as empresas possuem um setor de Controladoria e, sendo assim, esse papel deve ficar nas mãos do gestor que tiver mais visão sistêmica. (MOSIMAN e FISCH, 1999)

"A continuidade de uma empresa é mantida por meio de seus resultados. No momento em que a empresa apresentar resultado negativo, sua continuidade será comprometida." (MOSIMANN e FISCH, 1999, p. 116).

Garcia (2010) apresenta a Controladoria como o setor responsável pela preparação e excursão de um sistema integrado de informações operacionais e financeiras para, a partir das demonstrações contábeis e baseadas em uma estrutura adequada de controles internos, suprir os gestores com instrumentos de análise e controle gerencial, permitindo o alcance das metas organizacionais impostas pela administração.

Segundo Catelli (2001), a controladoria é uma área coordenadora das informações sobre gestão econômica; entretanto ela não substitui a responsabilidade dos gestores por seus resultados obtidos, mas busca aconselha-los à otimização do resultado econômico.

\section{Ferramentas da Controladoria}

Tendo em vista a importância da controladoria nas organizações, vale a pena listar algumas das ferramentas utilizadas durante o processo de controle. Sendo elas: (OLIVEIRA JR e SILVA, 2009; PADOVEZE, 2009; NAKAGAWA, 1993) 
a) Balanced Scorecard - É um sistema de gestão que complementa as medidas financeiras que procedem da visão e estratégia de cada empresa;

b) Gestão estratégica - Busca colaborar para que a empresa alcance seus objetivos através da direção dos recursos e da maximização das relações interpessoais;

c) Gestão estratégica de custos - Tem o objetivo de recuperar os custos ou gastos utilizados na fabricação dos produtos e obter lucro, sendo de extrema importância em qualquer organização;

d) Gestão financeira e orçamentária - Buscam antecipar a visualização dos resultados, que se forem executados de acordo com o planejado, deverão corresponder aos objetivos traçados; e

e) Sistemas de informações - É o conjunto de funções e processos que geram dados sobre alguma tarefa de trabalho.

\section{Controller}

De acordo com Nakagawa (1993) a pessoa responsável pelo projeto, implementação e manutenção de um sistema integrado de informações em uma empresa é o controller. Afirma ainda que:

Os modernos conceitos de Controladoria indicam que o controller desempenha sua função de controle de maneira muito especial, isto é, ao organizar e reportar dados relevantes, exerce uma força ou influência que induz os gerentes a tomarem decisões lógicas e consistentes com a missão e objetivos da empresa. (NAKAGAWA, 1993, p.13)

Para entender melhor a ação do Controller, Herckert e Wilson (apud Moisan e Fisch, 1999, p. 95 e 96) destaca algumas características essenciais para esta função, como: iniciativa, visão econômica, comunicação racional, síntese, visão para o futuro, oportunidade, persistência, cooperação, imparcialidade, persuasão, consciência das limitações, cultura geral, liderança e ética.

\section{DISCUSSÃO}

Conforme apresentado o mercado de franquias está crescendo cada vez mais no Brasil indo em direção contrária da economia brasileira. Sendo que a maior fatia desse mercado foi conquistada pelo setor de alimentação, seguido pelo educacional.

A falta de perfil empreendedor de uma grande parte dos franqueados brasileiros, juntamente com o desejo de não "começar do zero" tiveram papel importante no crescimento dessas franquias, pois a maioria não tem conhecimento suficiente sobre gestão de negócios e, por isso, sentem-se mais confortáveis para investir em um negócio com menos riscos de insucesso.

Outro fator relevante percebido nas leituras sobre o assunto, é que uma grande parte das franqueadas não tem um sistema próprio de Controladoria que é de extrema importância para a saúde financeira de qualquer negócio, inclusive no ramo de franquias.

A implantação de controles adequados, através do controller, coordenando o processo de planejamento das diversas áreas e atividades organizacionais, através de um sistema de informações que apoia todas as fases do processo decisório, facilita a ação dos gestores em suas rotinas de tomada de decisões.

A Controladoria é importante também, não apenas para a tomada das decisões, como, por ser uma fonte de informações, as quais devem ser confiáveis e seguras, são utilizadas por quase toda a organização, controlando os custos, as despesas, os investimentos e demais passivos, ajudando numa administração mais minuciosa, evitando perdas e gastos desnecessários. 
$\mathrm{Na}$ controladoria, quando uma decisão é tomada com base em um demonstrativo de resultado, os números melhoram ou alguma fonte de perdas é detectada e estancada, ou ainda outros milhões de opções.

Não há de se negar que, informação é poder. Este poder, na mão do empresário, é uma ferramenta que pode salvá-lo do precipício ou arremessá-lo mais afundo, por isso, deve ser confiável, segura e haver interpretação analítica bem fundamentada.

\section{CONSIDERAÇÕES FINAIS}

Apesar de ser um tema pouco explorado pelos pesquisadores brasileiros, o objetivo da pesquisa foi atingido, pois pode-se concluir que a Controladoria é de fundamental importância não só em empresas franqueadas, mas como em qualquer tipo de empresa.

Contudo, também foi observado que a maioria das empresas franqueadas precisa reorganizar suas estruturas e o processo de planejamento e controle, para dessa forma melhorar a administração e gerência dos custos e despesas financeiras e a otimização dos resultados.

Pode-se observar que a controladoria na empresa é uma peça fundamental, pois é onde são reunidas todas as informações, para a composição dos relatórios, e são esses documentos, que embasam a alta administração na tomada de decisão.

Com isso os benefícios que a empresa pode ter na ação da controladoria, é a avaliação dos resultados econômicos para que sejam atingidos os objetivos, e também assegurar a continuidade da empresa no mercado.

\section{REFERÊNCIAS BIBLIOGRÁFICAS}

BETO FILHO et al. Franchising: Aprenda com os especialistas=Franchising: Learn from the experts. 1. ed. Bilíngue. Rio de Janeiro: ABF-Rio, 2013.

CATELLI, Armando (coord.). Controladoria: uma abordagem da gestão econômica. 2a ed. São Paulo: Atlas, 2001.

CERVO, Amado Luiz; BERVIAN, Pedro Alcino. Metodologia Científica: para uso dos estudantes universitários. São Paulo: McGraw-Hill do Brasil, 1983.

FLEURY, P. F.; WANKE, P. F.; FIGUEIREDO, K. F. Logística empresarial: a perspectiva brasileira. São Paulo: Atlas, 2009

FRANQUIA FRANQUEADO FRANQUEADOR. SEBRAE. Disponível em: <https://www.sebrae. com.br/Sebrae/Portal\%20Sebrae/Anexos/franquias portal sebrae.pdf>. Acesso em 17 jul. 2017.

GARCIA, Alexandre Sanches. Introdução à controladoria: instrumento básico de controle de gestão das empresas. São Paulo: Atlas, 2010.

MARTINS, Fran; LIMA, Osmar Brina Corrêa. Contratos e obrigações comerciais: incluindo os contratos de representação comercial, seguro, arrendamento mercantil (leasing), faturização (factoring), franquia (franchising), know-how e cartões de crédito. 16.ed. atual. Rio de Janeiro: Forense, 2010.

MOSIMANN, Clara Pellegrinello; FISCH, Sílvio. Controladoria: Seu papel na administração de Empresas. 2. ed. São Paulo: Atlas, 1999. 
NAKAGAWA, Masayuki. Introdução à Controladoria: Conceitos, sistemas, implementação. 1. Ed. São Paulo: Atlas, 1993.

OLIVEIRA, Luís Martins de; JUNIOR, José Hernandez Perez; SILVA, Carlos Alberto dos Santos. Controladoria Estratégica. São Paulo: Atlas, 2009.

PADOVEZE, Clóvis Luís. Controladoria estratégica e operacional: Conceitos, estrutura, aplicação. 3. Ed. Ver. E atual. São Paulo: Cengage Learning, 2009.

PERFIL DAS 50 MAIORES FRANQUIAS NO BRASIL. ABF. Disponível em: <www.abf.com.br/estudoda-abf-revela-o-perfil-das-50-maiores-marcas-de-franquias-no-brasil/>. Acesso em: 20 jun. 2017.

SIMÃO FILHO, Adalberto. Franchising: aspectos jurídicos, e contratuais. São Paulo: Atlas, 1993.

SOUSA, Jorge Pedro. Elementos de Teoria e Pesquisa da Comunicação e dos Media. 2. ed. Porto: Edições Universidade Fernando Pessoa, 2006. 